\title{
Comparison of anesthetics in electroconvulsive therapy: an effective treatment with the use of propofol, etomidate, and thiopental
}

This article was published in the following Dove Press journal:

Neuropsychiatric Disease and Treatment

20 February 2014

Number of times this article has been viewed

\author{
Guy Sender Zahavi' \\ Pinhas Dannon ${ }^{1,2}$ \\ 'Sackler School of Medicine, Tel Aviy \\ University, Israel; ${ }^{2}$ Brain Stimulation \\ Unit at Beer Yaakov-Ness Ziona \\ Mental Health Center, Israel
}

Objectives: Electroconvulsive therapy (ECT) is considered to be one of the most effective treatments in psychiatry. Currently, three medications for anesthesia are used routinely during ECT: propofol, etomidate, and thiopental. The objective of this study was to evaluate the effects of the anesthetics used in ECT on seizure threshold and duration, hemodynamics, recovery from ECT, and immediate side effects.

Methods: Our study is a retrospective cohort study, in which a comparison was made between three groups of patients who underwent ECT and were anesthetized with propofol, etomidate, or thiopental. The main effect compared was treatment dose and seizure duration. All patients were chosen as responders to ECT.

Results: Data were gathered about 91 patients (39 were anesthetized with thiopental, 29 with etomidate, and 23 with propofol). Patients in the thiopental group received a lower electrical dose compared to the propofol and etomidate group (mean of $459 \mathrm{mC}$ compared to $807 \mathrm{mC}$ and $701 \mathrm{mC}$, respectively, $P<0.001$ ). Motor seizure duration was longer in the thiopental group compared to propofol and etomidate (mean of 40 seconds compared to 21 seconds and 23 seconds, respectively, $P=0.018$ ). Seizure duration recorded by electroencephalography was similar in the thiopental and etomidate groups and lower in the propofol group (mean of 57 seconds in both groups compared to 45 seconds, respectively, $P=0.038$ ).

Conclusion: Patients who were anesthetized with thiopental received a lower electrical treatment dose without an unwanted decrease in seizure duration. Thiopental might be the anesthetic of choice when it is congruent with other medical considerations.

Keywords: anesthesia, ECT, seizure

\section{Introduction}

Electroconvulsive therapy (ECT) is considered to be one of the most effective treatments in psychiatry. Currently, three medications for anesthesia are used routinely during ECT: propofol, etomidate, and thiopental. Our objective in this study was to evaluate the different effects of the anesthetics used in ECT in order to suggest the preferred anesthetic medication for this procedure.

We retrospectively compared three groups of patients who underwent ECT and were anesthetized with propofol, etomidate, or thiopental. All patients were chosen as clinical responders to ECT. We chose seizure threshold and duration, hemodynamics, recovery from ECT, and immediate side effects as the outcomes.

Our hypothesis was that the patients who were anesthetized with thiopental received a lower electrical treatment dose without an unwanted decrease in seizure duration. We concluded that thiopental might be the anesthetic of choice when it is congruent with other medical considerations.
Correspondence: Pinhas Dannon

Beer Yaakov, Israel

Fax +97289212570

Email pinhasd@post.tau.ac.il 
The opinions concerning ECT for a variety of psychiatric disorders are diverse, and they range from researchers who claim that there is a high probability that ECT is ineffective and causes long-term side effects ${ }^{1}$ to clinicians who claim that ECT is safe and is the most effective treatment in psychiatry. ${ }^{2,3}$ The indications for ECT are major depression, a manic state, acute psychosis, and catatonia. ${ }^{4}$ The treatment procedure is performed with short-term general anesthesia under the influence of neuromuscular-blocking medication by placing two electrodes on the temples and/or the forehead of the patient and delivering electrical pulses between the electrodes in order to induce a generalized convulsion. ${ }^{5}$

The physiological side effects and aftereffects of ECT include fatigue, generalized weakness, vertigo, amnesia, confusion, agitation, and headaches. ${ }^{6}$ The hemodynamic effects include an elevation in the systolic blood pressure and pulse rate, ${ }^{7}$ and in certain cases arrhythmias. ${ }^{8}$ The generalized convulsion causes myoclonic seizures, fractures, and dislocations of the spine and the long bones, and muscle and joint pain. ${ }^{9}$ The standard use of neuromuscular-blocking medication (eg, succinylcholine) prevents the fractures and dislocations noted above, but does not prevent muscle and joint pain. In addition, there is a potential for dental damage and lacerations of the oral cavity. Side effects that are attributed to stimulation of the vagus nerve are sialorrhea, nausea, and vomiting. Anticholinergic drugs (eg, atropine) are used to minimize these side effects. ${ }^{6}$

Anesthetics have been used in ECT since the 1950s. The anesthesia is used to avoid unpleasant feelings the patient may have during convulsion inducement; it prevents the sensation of general paralysis after the administration of neuromuscular-blocking drugs and lowers the opposition to therapy. ${ }^{10}$ The anesthetic of choice until the mid-2000s was methohexital because of its proven safety profile, effectiveness, and relatively low cost. ${ }^{4}$ However, a lack of availability of methohexital has led to the use of other anesthetics.

Propofol is an anesthetic that is administered intravenously for general anesthesia and is widely used for procedures done under anesthesia. ${ }^{11}$ This anesthetic causes a rapid and smooth entry into unconsciousness and is linked to a rapid regaining of consciousness. Propofol has a researchbased and accepted safety profile. Common side effects are cardiovascular depression, pain during injection, bradycardia, and apnea in the minutes after injection.

Etomidate is an anesthetic that is administered intravenously for sedation and general anesthesia. ${ }^{12}$ It enters the central nervous system rapidly and is cleared rapidly, which makes it effective for short-term anesthesia. Etomidate causes a decrease in the cerebral metabolic rate, cerebral blood flow, and intracranial pressure. It has been suggested in the past that etomidate has neuroprotective properties. ${ }^{13}$ Respiratory and cardiovascular function might be slightly depressed by etomidate in an insignificant manner. Regarding the endocrine system, it can cause adrenal suppression for a few hours and a decrease in the production of adrenocortical hormones such as cortisol. Additional side effects are nausea and vomiting during recovery from anesthesia, myoclonic activity, and pain during injection.

Thiopental is a barbiturate that is used for general anesthesia, for the treatment of ischemic brain injury, and for the treatment of neurosurgical situations such as high intracranial pressure. ${ }^{14}$ In high doses, it can be used to treat status epilepticus that is refractory to initial pharmacological treatment. Like etomidate, in the central nervous system thiopental causes a decrease in the cerebral metabolic rate, cerebral blood flow, and intracranial pressure. Its effects on the cardiovascular system are a decrease in the mean arterial blood pressure and a decrease in cardiac output. Significant side effects of thiopental are laryngeal spasm and respiratory depression. Benign allergic skin reactions are common, but a serious allergic reaction is rare.

In a comparison between propofol and etomidate, ${ }^{15}$ differences were found between motor seizure duration as observed by a physician and as recorded by electroencephalogram (EEG). Seizure durations were shorter for patients under the influence of propofol as compared to patients under the influence of etomidate. In addition, the recovery time and the length of stay in the recovery room were longer for patients anesthetized with etomidate, but these findings were not statistically significant. Propofol was also compared to thiopental, ${ }^{16}$ and seizure durations were also shorter for the propofol group (motor seizure duration and seizure duration on EEG). There was no evident difference in the clinical efficacy of ECT among patients anesthetized with different anesthetics. ${ }^{15,16}$ In a study that compared the effects of these three anesthetics on healthy subjects, etomidate had no influence on hemodynamic measures. ${ }^{17}$ Propofol and thiopental caused a decrease in systolic blood pressure and an increase in pulse rate in the minutes after injection.

\section{Study objective}

Our objective in this study was to compare the effects of the anesthetics used today for ECT (propofol, etomidate, and thiopental) on the course of treatment, hemodynamic measures, recovery time, and immediate side effects after treatment. According to previous research, we assumed that patients who were anesthetized with propofol would receive 
a higher electrical treatment dose, and their seizure duration would be shorter. We assumed that patients who were anesthetized with propofol and thiopental would show a smaller increase in pulse and blood pressure, which accompanies ECT. We had hypothesized that the recovery time might be shorter for patients anesthetized with propofol and thiopental. In addition, we would like to clarify the side effects profile for each anesthetic.

\section{Materials and methods}

This is a retrospective cohort study. Our study was approved by the Beer Yaakov-Ness Ziona Mental Health Center institutional review board.

\section{Study population}

The population sampled for this study comprises all the patients treated in the ECT unit in the Beer Yaakov-Ness Ziona Mental Health Center between the years 2008 and 2012. We gathered information about patients who met the following inclusion criteria: 1) was treated in the ECT unit between 2008 and $2012 ; 2$ ) had a good response to the treatment as evaluated clinically by the staff of the hospitalizing ward (ie, the patient was categorized as responsive to ECT); 3) anesthetized during ECT with propofol, etomidate, or thiopental; 4) over age 18 at time of treatment; 5) had three consecutive treatments with an identical treatment dose for a comparison among these treatments; 6) treated during hospitalization (because there is more available information on hospitalized patients); 7) all needed data were recorded in the patient's medical file.

\section{Study variables}

We gathered data about 91 patients (39 were anesthetized with thiopental, 29 with etomidate, and 23 with propofol). Patients in the thiopental group received a lower electrical dose compared to the propofol group and the etomidate group (mean of $459 \mathrm{mC}$ compared to $807 \mathrm{mC}$ and $701 \mathrm{mC}$, respectively, $P<0.001)$. Motor seizure duration was longer in the thiopental group compared to the propofol and etomidate groups (mean of 40 seconds compared to 21 seconds and 23 seconds, respectively, $P=0.018$ ). Seizure duration recorded by electroencephalography was similar in the thiopental and etomidate groups and lower in the propofol group (mean of 57 seconds in both groups compared to 45 seconds, respectively, $P=0.03$ ).

\section{ECT procedure}

All the patients were recruited from acute wards and completed a medical check-up before the ECT treatment. This work-up includes blood tests, chest X-ray, electrocardiogram, neurological examination, and general physician's and anesthesiologist's clearance. Patients with existing health problems need clearance from the specialist in order to undergo ECT treatment. After completing the work-up and signing the treatment consent form, patients were not allowed to eat or drink for 8 hours before the treatment. All patients received $1 \%$ intramuscular atropine 30 minutes before the treatment. ECT was performed according to criteria from The Practice of Electroconvulsive Therapy: Recommendations for Treatment, Training, and Privileging. ${ }^{4}$ The spECTrum 5000M (Mecta; Portland, OR, USA) machine was used to perform the electrical impedance.

The patients were divided into groups according to the anesthetic used during ECT: propofol, etomidate, or thiopental. The anesthesiologist selected each patient's anesthetic according to the patient's medical background, additional medications, time to recovery after the first treatment, and the patient's response to the anesthetic in the past. Thiopental was given $1.5 \times$ body weight $(120 \mathrm{mg}-200 \mathrm{mg})$, propofol $0.6 \times$ body weight $(60 \mathrm{mg}-100 \mathrm{mg})$, and etomidate $0.1 \times$ body weight $(8 \mathrm{mg}-12 \mathrm{mg})$ of the patient. The primary outcomes were the course of ECT: treatment electrical dose in $\mathrm{mC}$ and motor seizure duration as recorded by EEG. The effectiveness of the seizure was defined as minimum 25 seconds of clinical seizure and minimum 30 seconds of EEG-recorded seizure. The secondary outcomes were the effect on heart rate and blood pressure. We routinely used the blood pressure cuff method to measure the anesthetic depth and scoline administration. Additional outcomes were the amount of time until transfer to the recovery room and the frequency of side effects immediately after treatment. Sex, age at the first treatment in the study, and information about cardiovascular disease were gathered as possible confounders. For each patient, data were gathered about three consecutive treatments. All patients were treated with $1 \mathrm{mg}$ of atropine administered intravenously and a dose of succinylcholine (40, 50, 70, or $100 \mathrm{mg}$ according to the patient's weight and ethnicity, and the anesthesiologist's considerations), also administered intravenously. The three treatments undertaken for each patient were identical in regard to the type and dose of anesthetic, the dose of succinylcholine, and the dose of electrical treatment.

\section{Data sampling}

The data for this study were taken from the medical records archive in Beer Yaakov-Ness Ziona Mental Health Center. 
All the study variables are routinely documented by the staff in the ECT unit.

Patients who fit the inclusion criteria were identified by reviewing the medical records of all patients who were admitted for treatment in the ECT unit from June 2008 until October 2012. Data were gathered until there were enough patients in each study group according to the predefined sample size (detailed in the following section). The treatments included for each patient were the three most recent consecutive treatments with identical parameters.

\section{Statistical analysis}

Sample size was calculated using the software Power and Precision version 4.1 by SPSS (IBM Corporation, Armonk, NY, USA). Sample size calculation was done for a one-way analysis of variance test comparing three groups. A sample of 66 patients was calculated (22 in each group) in three groups. This would provide an effective size of 0.4 using Cohen's $F$-statistic, meaning that at least 40 percent of the variance in the dependent variable would be explained by the different anesthetic groups; we considered type 1 and type 2 error probabilities of 0.05 and 0.20 , respectively.

As previously stated, data were sampled from three consecutive treatments. The value taken for the statistical analysis was the average of the outcome in these treatments. For numerical variables analysis, we used the analysis of variance test. For categorical variables, we used the Pearson's chi-square test. In order to estimate the influence of confounding variables, we used a model of linear regression. All statistical analysis was done using SPSS software, version 19 (IBM Corporation).

\section{Results}

\section{Characteristics of the patients}

Between June and October 2012, data were gathered about 91 patients who fit the inclusion criteria for this study. The psychiatric diagnoses of all participants are displayed in Figure 1. The patients were divided as follows: 39 patients were anesthetized with thiopental during ECT, 29 patients with etomidate, and 23 patients with propofol. Characteristics of the different groups are shown in Table 1.

The propofol patient group was different from the other groups in a few characteristics. This group had a higher percentage of women ( $88 \%$ versus [vs] $61 \%$ and $59 \%$ in the thiopental and etomidate groups, respectively), a higher average age (62 vs 45 and 47 in the thiopental and etomidate groups, respectively), and a higher percentage of patients with cardiovascular disease ( $48 \%$ vs $26 \%$ and $14 \%$ in the
Table I Characteristics of all patients

\begin{tabular}{|c|c|c|c|}
\hline Characteristic & $\begin{array}{l}\text { Thiopental } \\
(\mathrm{N}=39)\end{array}$ & $\begin{array}{l}\text { Propofol } \\
(\mathrm{N}=23)\end{array}$ & $\begin{array}{l}\text { Etomidate } \\
(\mathrm{N}=29)\end{array}$ \\
\hline $\begin{array}{l}\text { Age during the first } \\
\text { treatment }{ }^{\ddagger} \text {, years* }\end{array}$ & $45 \pm 16$ & $62 \pm 8$ & $47 \pm 18$ \\
\hline Male sex, number $(\%)^{* *}$ & $15(39)$ & $3(12)$ & $17(59)$ \\
\hline \multicolumn{4}{|l|}{ Psychiatric diagnosis, number (\%) } \\
\hline Schizophrenia & $18(46)$ & $16(64)$ & $24(83)$ \\
\hline $\begin{array}{l}\text { Acute and transient } \\
\text { psychotic disorder }\end{array}$ & $2(5)$ & I (4) & 0 \\
\hline Schizoaffective disorder & $4(10)$ & $3(12)$ & I (3) \\
\hline Bipolar disorder & I (3) & 0 & I (3) \\
\hline Depressive episode & $6(15)$ & $3(12)$ & I (3) \\
\hline $\begin{array}{l}\text { Recurrent depressive } \\
\text { disorder }\end{array}$ & $8(20)$ & $2(8)$ & $2(7)$ \\
\hline $\begin{array}{l}\text { Cardiovascular disease", } \\
\text { number }(\%)^{* * *}\end{array}$ & $\begin{array}{l}10(26) \\
(\mathbf{N}=\mathbf{3 5})\end{array}$ & $\begin{array}{l}12(48) \\
(\mathbf{N}=\mathbf{2 3})\end{array}$ & $\begin{array}{l}4(14) \\
(\mathbf{N}=\mathbf{2 8})\end{array}$ \\
\hline $\begin{array}{l}\text { Systolic blood pressure } \\
\text { before treatment, } \mathrm{mmHg}^{\dagger}\end{array}$ & $139 \pm 20$ & $|48 \pm 2|$ & $148 \pm 24$ \\
\hline $\begin{array}{l}\text { Diastolic blood pressure } \\
\text { before treatment, } \mathrm{mmHg}^{\dagger}\end{array}$ & $\begin{array}{l}84 \pm 9 \\
(N=33)\end{array}$ & $\begin{array}{l}85 \pm 11 \\
(\mathbf{N}=\mathbf{2 2})\end{array}$ & $\begin{array}{l}89 \pm 14 \\
(\mathbf{N}=\mathbf{2 8})\end{array}$ \\
\hline $\begin{array}{l}\text { Heart rate before treatment, } \\
\text { beats per minute }\end{array}$ & $94 \pm 16$ & $99 \pm 21$ & $101 \pm 15$ \\
\hline
\end{tabular}

Notes: The symbol \pm is used to describe an average and standard deviation; the average is on the left side. *Statistically significant difference in one-way analysis of variance test $(P<0.001)$; **statistically significant difference in Pearson's chisquare test $(P=0.002)$; *** statistically significant difference in Pearson's chi-square test $(P=0.019)$; tan average of three consecutive treatments with identical treatment dose; "the first out of three treatments sampled for this study; "cardiovascular disease includes diabetes, dyslipidemia, and chronic hypertension.

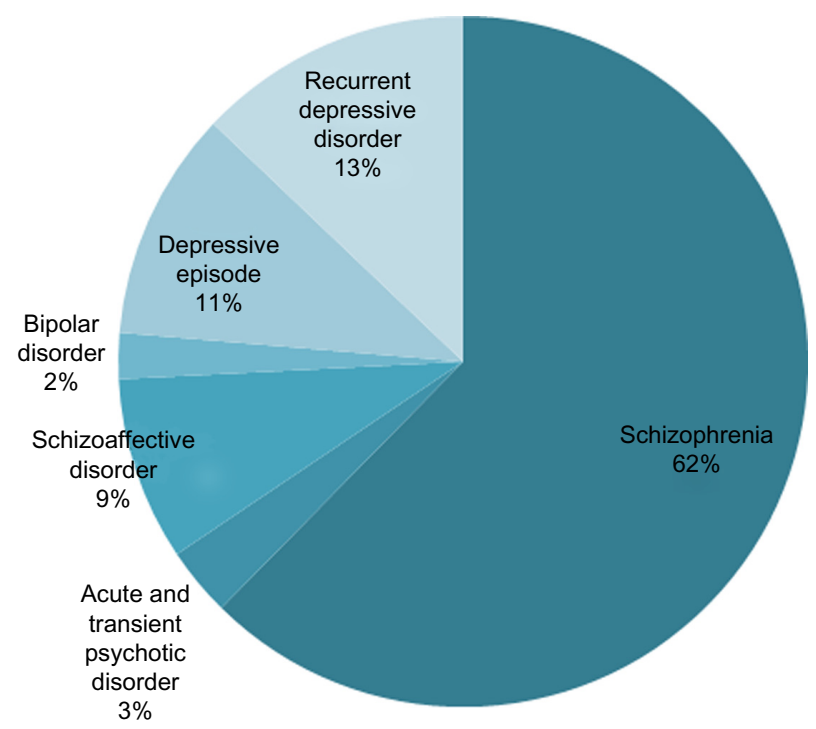

Figure I Psychiatric diagnoses according to the International Classification of Diseases (ICD) 10 for all patients.

thiopental and etomidate groups, respectively). The anesthetic used for ECT is chosen by the anesthesiologist in a nonrandomized manner, and that might explain the differences in characteristics between the groups. 
Table 2 Outcomes*

\begin{tabular}{|c|c|c|c|c|c|c|c|}
\hline \multirow[t]{2}{*}{ Outcome } & \multicolumn{2}{|c|}{ Thiopental } & \multicolumn{2}{|c|}{ Propofol } & \multicolumn{2}{|c|}{ Etomidate } & \multirow[t]{2}{*}{$P$-value } \\
\hline & $\mathbf{N}$ & Average \pm SD & $\mathbf{N}$ & Average \pm SD & $\mathbf{N}$ & Average \pm SD & \\
\hline Treatment dose, $\mathrm{mC}$ & 39 & $459 \pm 308$ & 23 & $807 \pm 406$ & 29 & $70 I \pm 397$ & $<0.00 I^{\ddagger}$ \\
\hline Motor seizure duration, seconds & 32 & $40 \pm 12$ & 21 & $32 \pm 8$ & 23 & $34 \pm 13$ & $0.018^{\ddagger}$ \\
\hline Seizure duration recorded on EEG & 35 & $57 \pm 16$ & 21 & $45 \pm 16$ & 25 & $57 \pm 23$ & $0.038^{\ddagger}$ \\
\hline $\begin{array}{l}\text { Change in systolic blood } \\
\text { pressure, } \mathrm{mmHg}^{\dagger}\end{array}$ & 30 & $14 \pm 12$ & 23 & $12 \pm 20$ & 28 & $9 \pm 19$ & 0.47 \\
\hline $\begin{array}{l}\text { Change in diastolic blood } \\
\text { pressure, } \mathrm{mmHg}^{\dagger}\end{array}$ & 29 & $8 \pm 13$ & 23 & $5 \pm 12$ & 28 & $-|.4 \pm 1|$ & $0.016^{\ddagger}$ \\
\hline $\begin{array}{l}\text { Change in heart rate, } \\
\text { beats per minute }{ }^{\dagger}\end{array}$ & 29 & $2 \pm 18$ & 18 & $1 \pm 19$ & 27 & $-11 \pm 14$ & $0.013^{\ddagger}$ \\
\hline $\begin{array}{l}\text { Time until transfer to } \\
\text { recovery room, minutes }\end{array}$ & 20 & $11 \pm 4$ & 11 & $11 \pm 3$ & 15 & $12 \pm 2$ & 0.61 \\
\hline & $\mathbf{N}$ & Number (\%) & $\mathbf{N}$ & Number (\%) & $\mathbf{N}$ & Number (\%) & $P$-value \\
\hline $\begin{array}{l}\text { Number of patients who experienced } \\
\text { agitation after treatment }\end{array}$ & 39 & $6(15)$ & 23 & $2(9)$ & 29 & $6(2 I)$ & 0.43 \\
\hline
\end{tabular}

Notes: *For each patient, the data used for statistical analysis is the average of the outcome in three consecutive treatments; tchange was calculated by subtracting the value before treatment from the value after treatment; "statistically significant difference in a one-way analysis of variance test.

Abbreviations: EEG, electroencephalography; SD, standard deviation.

\section{Treatment course}

Outcome variables are listed in Table 2. Stimulus dosage was $459 \pm 308 \mathrm{mC}$ with thiopental, and was higher with propofol $(807 \pm 406 \mathrm{mC})$ and etomidate $(701 \pm 397 \mathrm{mC})$. Patients' average clinical seizure time was $40 \pm 12$ seconds with thiopental, $32 \pm 8$ seconds with propofol, and $34 \pm 13$ seconds with etomidate. EEG-recorded seizure time was $57 \pm 16$ seconds with thiopental, $45 \pm 16$ seconds with propofol, and $57 \pm 23$ seconds with etomidate. There was a statistically significant difference among the groups in the electrical treatment dose and seizure duration. Patients in the thiopental group received a lower treatment dose compared to the other groups $(P<0.001)$. In addition, motor seizure duration was higher in the thiopental group $(P=0.018)$. The seizure duration on EEG was similar in the thiopental and etomidate group and lower in the propofol group $(P=0.038)$.

Patients who were anesthetized with propofol were believed to receive a higher treatment dose, but in actual fact patients in the propofol and etomidate groups received similar treatment doses, and patients in the thiopental group were treated with a lower dose. Also, we assumed that patients who were anesthetized with propofol would experience shorter seizures, but the average motor seizure duration was similarly lower in the propofol and etomidate groups. On the other hand, average seizure duration as recorded on EEG was lower in the propofol group alone. The discrepancy between average motor seizure duration and average seizure duration on EEG is relevant to clinicians and is probably related to the physician's observation of the patient. However, we do not believe that there might be an observational confirmation bias in clinically assessing motor seizure time.

\section{Hemodynamic changes}

Diastolic blood pressure remained stable in the etomidate group, as opposed to an elevation after treatment in the other groups $(P=0.016)$. Systolic blood pressure was elevated after treatment in all three groups. Pulse rate decreased in the etomidate group after treatment and remained stable in the other groups $(P=0.013)$.

In regards to hemodynamic changes, the study results are contrary to our expectations. We assumed that in the etomidate group, there would be a more significant elevation in blood pressure and pulse, but in actual fact, there was a decrease in diastolic blood pressure and a decrease in heart rate. It is possible that these outcomes, which were not anticipated considering past studies, arose from differences among the groups that we have not described in this retrospective study. Surprisingly, etomidate seemed to have a similar effect on blood pressure as other anesthetics.

\section{Course after treatment}

Time until transfer to the recovery room was almost identical among the three groups. Regarding immediate side effects, the only side effect documented was agitation. There was no difference in the percentage of patients who experienced side effects among the three groups.

\section{Confounders}

The possible effects of confounding variables were evaluated using linear regression (results are listed in Table 3).

We evaluated as confounders variables that were correlated with one or more of the treatment groups. The variables are age during the first treatment in the study, sex, and 
Table 3 Linear regression results for possible confounders

\begin{tabular}{|c|c|c|c|c|c|c|c|}
\hline $\begin{array}{l}\text { Independent variable } \\
\text { Confounder }\end{array}$ & $\mathbf{N}$ & F-value & $P$-value & $\begin{array}{l}\text { Unstandardized } \\
\text { effect (B) }\end{array}$ & SD & $t$-value & $P$-value \\
\hline Treatment dose & 91 & 7.363 & $>0.001 *$ & & & & \\
\hline Age during first treatment & & & & $8.6 \mathrm{mC} /$ year & 2.7 & 3.189 & $0.002 * *$ \\
\hline Female sex & & & & $101.8 \mathrm{mC}$ & 85 & I.198 & 0.234 \\
\hline Cardiovascular disease & & & & $-112.2 \mathrm{mC}$ & 96.2 & -1.166 & 0.247 \\
\hline Motor seizure duration & 76 & 3.376 & $0.009 *$ & & & & \\
\hline Age during first treatment & & & & $-0.2 \mathrm{sec} /$ year & 0.1 & -2.357 & $0.021 * *$ \\
\hline Female sex & & & & $-1.157 \mathrm{sec}$ & 3.3 & -0.351 & 0.726 \\
\hline Cardiovascular disease & & & & $0.68 \mathrm{I} \mathrm{sec}$ & 3.1 & 0.217 & 0.829 \\
\hline Seizure duration on EEG & 81 & 2.619 & $0.031 *$ & & & & \\
\hline Age during first treatment & & & & $-0.2 \mathrm{sec} /$ year & 0.2 & -1.315 & 0.192 \\
\hline Female sex & & & & $-8.2 \mathrm{sec}$ & 4.7 & -1.756 & 0.083 \\
\hline Cardiovascular disease & & & & $3.377 \mathrm{sec}$ & 5.4 & 0.626 & 0.533 \\
\hline Change in diastolic blood pressure $^{\dagger}$ & 80 & 3.147 & $0.012 *$ & & & & \\
\hline Age during first treatment & & & & $-0.2 \mathrm{mmHg} /$ year & 0.1 & -2.003 & 0.049 \\
\hline Female sex & & & & $5.6 \mathrm{mmHg}$ & 3.2 & 1.75 & 0.084 \\
\hline Cardiovascular disease & & & & $-2.5 \mathrm{mmHg}$ & 3.6 & -0.691 & 0.492 \\
\hline Change in heart rate ${ }^{\dagger}$ & 74 & 2.653 & $0.03 *$ & & & & \\
\hline Age during first treatment & & & & $-0.2 \mathrm{bpm}^{\ddagger}$ & 0.2 & -1.346 & 0.183 \\
\hline Female sex & & & & $6.3 \mathrm{bpm}$ & 4.8 & $\mathrm{I} .333$ & 0.187 \\
\hline Cardiovascular disease & & & & 6.1 bpm & 5.5 & 1.097 & 0.276 \\
\hline
\end{tabular}

Notes: *Statistically significant difference in one-way analysis of variance; ${ }^{* *}$ statistically significant difference for a two-tailed $t$-test $(P<0.05)$; ${ }^{\dagger}$ change was calculated by subtracting the value before treatment from the value after treatment.

Abbreviations: bpm, beats per minute; EEG, electroencephalography; SD, standard deviation; sec, seconds.

cardiovascular disease. Age was the only variable found to have a statistically significant effect.

In addition to the anesthetic used, age was found to have an effect on the average treatment dose and on motor seizure duration. This effect does not explain the similarity between the propofol and etomidate groups or the difference from the thiopental group and could be related to the basic difference in characteristics between the study groups.

\section{Discussion}

According to our PubMed/Ovid/ResearchGate search, only a few articles have been published that compared these three anesthetics in ECT treatment. Our study aimed to demonstrate differences among these three agents. A retrospective study by Eser et al ${ }^{18}$ compared these anesthetics' effects in ECT, but it included also patients anesthetized with methohexital. The authors concluded that thiopental and propofol are the most suitable induction agents during ECT.

A small randomized double-blind study $(\mathrm{N}=30)$ by Rosa et al ${ }^{19}$ compared the effects of propofol, etomidate, and thiopental in ECT, but regarded only the cardiovascular effects; no differences were found. Another study by Rosa et $\mathrm{al}^{20}$ with the same sample size compared the effects of these three medications on ECT, but mainly regarded recovery time. Propofol seemed to have the best recovery profile.

In our study, there was a statistically significant difference in the treatment course (as measured by treatment dose and seizure duration) among the groups. Patients who were anesthetized with thiopental received a lower treatment dose without an unwanted decrease in seizure duration; therefore, we conclude that thiopental might be the anesthetic of choice when other medical considerations allow its use. Etomidate caused a decrease in pulse rate after ECT and stabilized the diastolic blood pressure; however, this finding was not expected in light of the current literature. ${ }^{17}$ In order to continue studying this issue, there is a need for research in which the difference among the groups can be neutralized (using randomization or case-control studies). There were no differences in the course of recovery among the different anesthetics.

The power of this study is that it was conducted in one electroconvulsive therapy unit with much experience in treating and following psychiatric patients. Because standard and common measures were used, the inner validity of this study should be high. In addition, because the assumptions and study population are well defined, conclusions can be made about similar populations undergoing ECT. Nonetheless, this study has weak points as well. First of all, this is a 
retrospective study without randomization of patients to study groups, and thus it might have a selection bias. This is also a study without blinding, so it might have an observational confirmation bias as well. In addition, in the patient's medical records there is only a brief report of the influence of ECT on their clinical or psychiatric states in a way that can be gathered and assessed for research. From the medical records, it can be inferred that the patients responded in a positive manner to ECT, but there are no questionnaires or reporting templates that might give a more objective assessment of their clinical states. It is important to mention that previous studies found no difference in the efficacy of ECT when using different anesthetics. ${ }^{15,16}$

\section{Conclusion}

Thiopental might be the proper medication for induction in ECT when other medical considerations allow its use. We hope that this study will help medical professionals to choose the best anesthetic for each patient.

\section{Acknowledgment}

This research was performed without funding from an academic or commercial body.

\section{Disclosure}

The authors declare no conflicts of interest in this work. This study was a part of GSZ education program at the Sackler School of Medicine, Tel Aviv University.

\section{References}

1. Sterling P. ECT damage is easy to find if you look for it. Nature. 2000;403(6767):242.

2. UK ECT Review Group. Efficacy and safety of electroconvulsive therapy in depressive disorders: a systematic review and meta-analysis. Lancet. 2003;361(9360):799-808.

3. Fink M. ECT has proved effective in treating depression. Nature. 2000;403(6772):826.
4. American Psychiatric Association Committee on Electroconvulsive Therapy. Treatment procedures. In: The Practice of Electroconvulsive Therapy: Recommendations for Treatment, Training, and Privileging. 2nd ed. Washington, DC, USA: American Psychiatric Association, 2001. p. 133.

5. Fink M, Taylor MA. Electroconvulsive therapy. JAMA. 2007; 298(3): 330-332.

6. Ding Z, White PF. Anesthesia for electroconvulsive therapy. Anesth Analg. 2002;94(5):1351-1364.

7. Wells DG, Davies GG. Hemodynamic changes associated with electroconvulsive therapy. Anesth Analg. 1987;66(11):1193-1195.

8. Larsen JR, Hein L, Strömgren LS. Ventricular tachycardia with ECT. JECT. 1998;14(2):109-114.

9. Herriot PM, Cowain T, McLeod D. Use of vecuronium to prevent suxamethonium-induced myalgia after ECT. Br J Psychiatry. 1996;168(5):653-654.

10. Steven RJ, Tovel RM, Johnson JC, Delgado E. Anesthesia for electroconvulsive therapy. Anesthesiology. 1954;15(6):623-636.

11. Abad-Santos F, Gálvez-Múgica MA, Santos MA, et al. Pharmacokinetics and pharmacodynamics of a single bolus of propofol $2 \%$ in healthy volunteers. J Clin Pharmacol. 2003;43(4):397-405.

12. Avramov MN, White PF. Etomidate: its pharmacological and physiologic effects. Semin Cardiothorac Vasc Anesth. 1997;1(2):132-141.

13. Ostwald P, Doenicke AW. Etomidate revisited. Curr Opin Anaesthesiol. 1998;11(4):391-398.

14. Russo H, Bressolle F. Pharmacodynamics and pharmacokinetics of thiopental. Clin Phramacokinet. 1998;35(2):95-134.

15. Avramov MN, Husain MM, White PF. The comparative effects of methohexital, propofol, and etomidate for electroconvulsive therapy. Anesth Analg. 1995;81(3):596-602.

16. Swaim JC, Mansour M, Wydo SM, Moore JL. A retrospective comparison of anesthetic agents in electroconvulsive therapy. $J E C T$. 2006;22(4):243-246.

17. Gauss A, Heinrich H, Wilder-Smith OH. Echocardiographic assessment of the haemodynamic effects of propofol: a comparison with etomidate and thiopentone. Anaesthesia. 1991;46(2):99-105.

18. Eser D, Nothdurfter C, Schüle C, et al. The influence of anaesthetic medication on safety, tolerability and clinical effectiveness of electroconvulsive therapy. World J Biol Psychiatry. 2010;11(2 Pt 2): 447-456.

19. Rosa MA, Rosa MO, Marcolin MA, Fregni F. Cardiovascular effects of anesthesia in ECT: a randomized, double-blind comparison of etomidate, propofol, and thiopental. J ECT. 2007;23(1):6-8.

20. Rosa MA, Rosa MO, Belegarde IM, Bueno CR, Fregni F. Recovery after ECT: comparison of propofol, etomidate and thiopental. Rev Bras Psiquiatr. 2008;30(2):149-151.
Neuropsychiatric Disease and Treatment

\section{Publish your work in this journal}

Neuropsychiatric Disease and Treatment is an international, peerreviewed journal of clinical therapeutics and pharmacology focusing on concise rapid reporting of clinical or pre-clinical studies on a range of neuropsychiatric and neurological disorders. This journal is indexed on PubMed Central, the 'PsycINFO' database and CAS

\section{Dovepress}

The manuscript management system is completely online and includes a very quick and fair peer-review system, which is all easy to use. Visit http://www.dovepress.com/testimonials.php to read real quotes from published authors. 